\title{
An isolated premature menarche in 18 months girl
}

\author{
Joshi Suyajna $\mathrm{D}^{1}$, Veerendrakumar C $\mathrm{M}^{2}$, Madhu Y R $\mathrm{R}^{3}$ \\ Department of Obstetrics and Gynecology, Head Quarter Hospital, Ananthpur road, \\ Vijayanagara Institute of Medical Sciences, Bellary- 583103, Karnataka. India. \\ 1 Professor and Head, 2 Professor, 3 Post graduate student
}

\section{Introduction:}

Isolated premature menarche is a rare unusual event of cyclic vaginal bleeding in the absence of development of secondary sexual characters. The cause remains unclear but may be related to unusual endocrine sensitivity of the endometrium to the low levels of estrogens. We report a rare case of isolated premature menarche in an 18 months old girl. Till date very few cases have been reported.

\section{Case details:}

An 18 months girl born on 23/4/12 after a normal full term delivery began to have cyclical vaginal bleeding at 12 months of age lasting for 4-5days and recurred every 3-4 weeks. There was no h/o local trauma/sexual abuse/foreign body insertion / easy bruisability.Her bladder and bowel habits were regular.She was not on any medication. Her neonatal history and developmental mile stones were normal.

On examination baby's weight was $10 \mathrm{~kg}$ (50th percentile of CDC chart) and height was $76 \mathrm{~cm}$ (3rd percentile of CDC chart). There was no evidence of secondary sexual characters [picture 1]. Otherwise general and systemic examination was unremarkable. Local examination revealed normal genitalia for her age. Labia majora and Labia minora were normal [picture 2]. Urethral orifice appeared normal.

\section{Investigations:}

Haemoglobin-8.8gm\%, WBC count-12,600cells $/ \mathrm{mm}^{3}$, platelet count-3, 79,000/cu mm. $\mathrm{T}_{3}-1.63 \mathrm{ng} / \mathrm{ml}$,

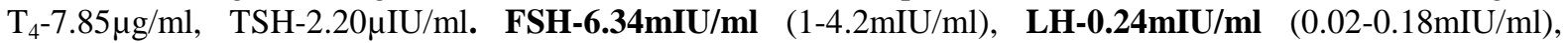
S.Estradiol- $<9.00 \mathrm{pg} / \mathrm{ml}$ (7-21 pg/ml).Prolactin- $12.12 \mathrm{ng} / \mathrm{ml}$. Testosterone- $0.13 \mathrm{ng} / \mathrm{ml}$. Progesterone- $0.37 \mathrm{ng} / \mathrm{ml}$. DHES- $10.1 \mathrm{mcg} / \mathrm{ml}$. Radiological skeletal age corresponded to the chronological age. USG - uterus and ovaries were normal. CT Brain was normal. Vaginoscopy was done under general anesthesia using $30^{\circ} 5 \mathrm{~mm}$ hysteroscope on 9/10/13. Vagina and cervix appeared normal without any foreign body /local lesions [picture 3].

\section{Discussion:}

Cyclic vaginal bleeding in the absence of other signs of secondary sexual development was described in 4 girls by Heller et al and given the name of premature menarche.In this condition girls begin periodic vaginal bleeding at age 1 to 9 years. Etiology is uncertain but may be due to premature activation of the hypothalamic-pituitary-ovarian axis resulting in FSH secretion and increased sensitivity of endometrium to estradiol level, which are too low to produce breast development [1]. There is a predominance of FSH secretion but the gonadotropin secretion is not characteristic of true premature puberty [2]. Before the diagnosis of premature menarche is made, sexual abuse, local trauma, foreign body insertion and genital neoplasms like botryoid sarcoma or hormonally active ovarian tumors must be excluded.

Isolated menarche may appear before other manifestations of sexual precocity in McCune-Albright syndrome and in the premature sexual maturation that can occur in juvenile hypothyroidism [3, 4].

D Murram et al [5] obtained follow up information from 12 women aged 16-34 years who had been seen previously because of premature isolated menarche starting between ages 9 months and 9 years. All the women reported normal regular menses and fertility was normal in 6 women who had married. According to Heller et al the bleeding can recur for 1 to 6 years and then cease.

This case is similar to case described by Blunck etal [4] in review of transient sexual precocity.Huffman also described 2 such patients and referred to their clinical course [6].

In our case, FSH and LH were slightly raised, leading to isolated early menstruation, possibly related to hyper responsive endometrium to low levels of estrogens. At the time of writing this case report the girl did not have bleeding for the last 12 weeks. This could be due to spontaneous resolution of the symptoms. 


\section{Conclusion:}

Isolated premature menarche is a rare event probably related to hyper responsive endometrium.The condition does not require any specific treatment as it is self-limiting and has no long term effect on growth, menstrual and fertility pattern.

\section{Reference:}

[1]. Heller ME, Dewhurst J, Grant DB: Premature menarche without other evidence of precocious puberty. Arch DisChild 1979; 54:472-475.

[2]. Saggese G, Ghirri P, Del Vecchio A, et al: Gonadotropin pulsatile secretion in girls with premature menarche. Horm Res 1990; 33:5-10

[3]. Sigurjonsdottir TJ, Hayles AB. Precocious puberty. A report of 96 cases. Am J Dis Child. 1968 Mar; 115(3):309-321.

[4]. Blunk, W, Bierich, J.R, and Bettendorf, A (1967). Uber fruhreife III. Mitteilung. Idiopathische pubertas praecox, and premature thelarche 115, 555-563

[5]. D Murram, John Dewhurst and D B Grant. Premature menarche: a follow -up study, Archives of disease in childhood, 1983, 58,142-156.

[6]. Huffman, J.W (1968).The Gynecology of childhood and adolescence, p.352. Saunders: Philadelphia.

\section{Picture 1}

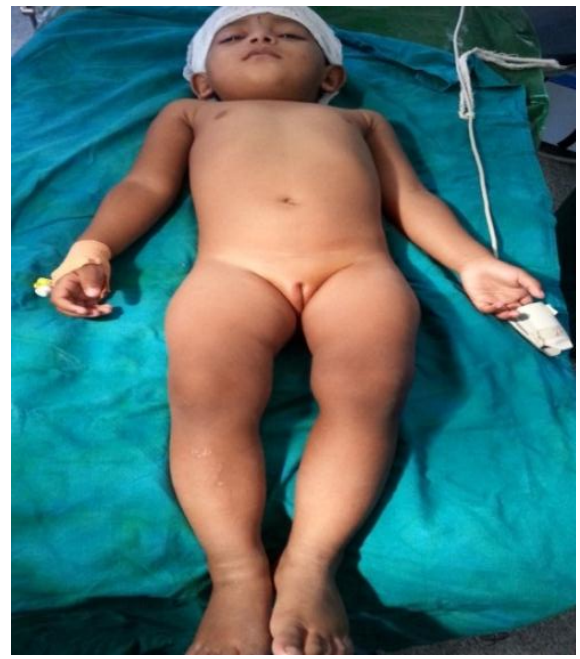

Picture 2

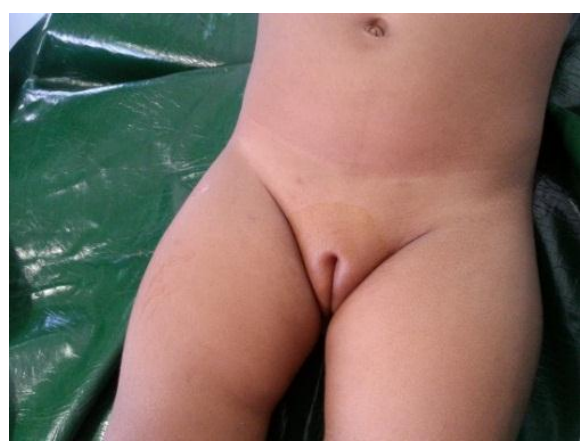

Picture 3

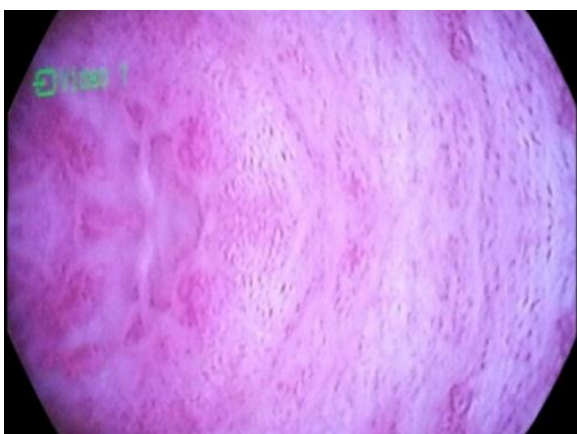

